\title{
THE DEVELOPMENT OF THE COURSE EXPERIENCE QUESTIONNAIRE AND REVISED-STUDY PROCESS QUESTIONNAIRE FOR PART-TIME LEARNERS ON BLENDED, VOCATIONALLY RELEVANT, DEGREE PROGRAMMES
}

\author{
Andrew Youde \\ University of Huddersfield (UNITED KINGDOM)
}

\begin{abstract}
This paper outlines the development of two prominent questionnaires that consider teaching and learning quality in higher education (HE) contexts. These questionnaires were originally designed for full-time students with examinations as a significant proportion of their course assessment. They have been developed for blended learning, vocationally relevant degree courses that are aimed at part-time students. The Course Experience Questionnaire (CEQ) was designed as an indicator of teacher effectiveness on courses in HE institutions and draws on learners' perceptions of teaching, curriculum and assessment. The Revised Study Process Questionnaire (R-SPQ) was designed to evaluate learners' approaches and motivation towards their study. The paper describes the steps taken to develop these questionnaires, including validity and reliability considerations, for this emerging and significant context. These steps comprised a process of piloting and subsequent testing with 72 learners on corresponding degree courses within an education disciplinary area. The revised questionnaires are presented and would support tutors and course leaders evaluating their practices within this context. Further, suggestions are made to further improve the validity and reliability of the questionnaires for future research in this area.
\end{abstract}

Keywords: Blended Learning, Course Experience Questionnaire (CEQ), Revised Study Process Questionnaire (R-SPQ), Part-time Learners, Adult Learners.

\section{INTRODUCTION}

The Course Experience Questionnaire (CEQ) [1] and the Revised Study Process Questionnaire (RSPQ) [2] are prominent questionnaires that explore teaching and learning practices within higher education (HE) contexts. Both have been used extensively, but, commonly, in traditional, face-to-face higher education contexts, with examinations forming a significant proportion of the course assessment. This paper reports the development of these questionnaires for blended learning, vocationally relevant, part-time (PT) degree courses, within the United Kingdom (UK).

Blended learning typically involves significant online teaching, learning and support, but includes some face-to-face contact [3]. The questionnaires were developed as part of a research study in the practices of HE tutors in blended learning contexts [4] [5] [6], and they can support course leaders when evaluating practices in this area.

The paper firstly outlines the context for the questionnaire development before providing background information about both the CEQ and R-SPQ, and the steps taken to modify them for blended learning courses. A discussion of validity and reliability follows before the revised questionnaires are presented. Finally, areas for further development and improvement are considered.

\section{RESEARCH CONTEXT}

The research study was based at a university in the north of England, which has approximately 500 fulltime academic staff and 19,000 students. Blended learning delivery models were used on each course investigated and all were located in the School of Education, therefore, focused on this particular subject area. The courses adopted a day school model of delivery where learners typically attend classes one day per month with the remaining time spent studying independently, utilising resources held on the virtual learning environment (VLE). The research conducted a detailed exploration of eight tutors' practice on one of their modules, which are usually a term in length (approximately three to four months) from the first day school until learners submit summative assessments. Each module, therefore, has two or three day schools. A random selection of students ( $n=72$ covering the eight modules investigated) 
completed the questionnaires. These responses formed the basis of the analysis regarding the questionnaires' validity and reliability in this particular context.

\section{COURSE EXPERIENCE QUESTIONNAIRE}

The CEQ [1] was designed as an indicator of teacher effectiveness on courses within HE institutions and draws on learners' perceptions of teaching, curriculum and assessment. It was originally designed for courses with traditional approaches to teaching that had more regular tutor/learner contact than blended models typically afford. However, the questionnaire has been modified to make it suitable for an individual tutor (see [7] for a similar use of the CEQ) and a blended teaching model (see [6] and [7] for a similar use of the CEQ in distance education). Kreber [7] used a 23-item version of the CEQ in her study to explore the relationship between students' course perception and approaches to study in undergraduate science courses. In North America, where Kreber's study was based, a course was interpreted as "a semester-long seminar or lecture usually comprising thirty-six hours of class time and taught by one instructor" [7: 62], therefore, similar to a module of study in UK HE. Consequently, this version of the CEQ informed the development of the questionnaire for this study.

The scale items adopted were largely the same as the original CEQ, but adapted in line with Richardson and Woodley's [8], Kreber's [7] and Richardson's [9] studies, and were:

- Good Teaching: communication;

- Good Teaching: feedback on, and concern for, student learning;

- Clear Goals and Standards;

- Appropriate Workload;

- Appropriate Assessment.

These scale items summarise what could be considered to be effective blended tutors and tutoring. The Good Teaching scale items cover what the literature (for example: see, [10]; [11]) outline as a 'good teacher', particularly as the statements cover both delivery and feedback on learners' work, and Lizzio et al. [12] found that the original CEQ factor, Good Teaching, significantly predicted student summative achievement. Kreber [7] amended the original CEQ Good Teaching scale with two factors, which she categorised as Feedback on, and Concern for, Student Learning and Classroom Teaching, both of which have relevance for a blended learning context. Kreber's Classroom Teaching scale was adapted to the Good Teaching Communication scale to include statements about clear communication, motivational comments to improve work, and tutors making the subject interesting. Clear goals and standards, together with good teaching, were also found to have an impact on academic achievement [13]. Appropriate student workload would appear to be a feature of good teaching particularly as a heavy student workload is associated with Surface approaches to learning [14] [15] (see Section 4 for a definition of Surface learning). Whilst formative assessments are more likely to be under tutor control, summative assessments in UK HE are developed by module and course leaders in conjunction with course approval committees. Appropriate Assessment naturally has the same consideration as appropriate student workload. However, perceptions of tutors are important given the vocational nature of the courses targeted and that assessments are relevant for these particular learners' needs, and that they generally meet adult learner needs [16]. There is value in obtaining learners' perceptions of appropriate student workload and appropriate assessments as the tutor's handling of these aspects provide data on their qualities as a tutor within a blended learning context.

\section{REVISED STUDY PROCESS QUESTIONNAIRE}

Vermetten et al. [17] found that the quality of teaching could impact on learners' approach to studying and it is assumed this would be similar for blended learning courses. Biggs et al. [2] Revised Study Process Questionnaire (R-SPQ) measures learners' approaches and motivation towards their study. This questionnaire is appropriate for learners in western universities, with acceptable validity and reliability [18] [19]. Zeegers [20] also highlighted the reliability of the R-SPQ and gave reasons why he felt the original Study Process Questionnaire (SPQ) needed revisiting. These mainly focussed on the changing nature of HE in Australia and these factors (a more diverse student body, increased cost to student, changes to content delivery and assessment due to funding cuts, increased use of technology) are mirrored in UK HE. These changes, plus the R-SPQ's emphasis on effective teaching [2], make the instrument suitable for PT students on vocationally orientated programmes, particularly with regard to a changing student body (more part-time, mature students), and the impact of technology on delivery and assessment. 
Marton and Säljö [21] identified predominant approaches to learning and outlined the notion of Deep and Surface learners, which are influenced by the content, context and requirements of a specific task. Students adopting deeper approaches use the highest level of learning activities [2: 138], such as, wide reading and relating concepts to work environments, whereas those adopting surface approaches complete only the required activities in order to achieve desired outcomes. Biggs and Tang [22: 24] outline the benefits for tutors when students adopt Deep approaches when they state "they automatically try to focus on underlying meanings, on main ideas, themes, principles, or successful applications". Kember, Leung, and McNaught [23] develop these ideas by considering influencing factors. They state:

\title{
the relational nature of approaches to learning imply that the curriculum design and the nature of the teaching and learning environment have some bearing on the learning approach the student adopts. [23: 45].
}

This suggests that identifying learners' approach to study is a factor in understanding their evaluation of a module of study, but it may be difficult for tutors to influence within a relatively short, contained learning experience. Biggs and Tang [22: 24] state that even with the best teaching some learners will adopt Surface approaches and also considering outside influences on adults, such as family and work pressures, it is necessary to account for the impact of approaches to study when evaluating modules for part-time learners. Biggs and Tang [22: 25] add to these points and associate the following tutor influences with the Deep approach, an appropriate motivational context, assessing for structure and not facts, and aligning teaching and learning methods to the intended outcomes of the module. Further, Gibbs [15:9] articulates characteristics of teaching and learning environments, which tend to encourage a Surface approach:

- a heavy student workload;

- an excessive amount of course material;

- a lack of opportunity to pursue subjects in depth;

- a lack of choice over subjects and the method of study;

- an anxiety provoking assessment system.

The R-SPQ consists of Likert scale questions (five-item), with a score of 1 to 5 being attributed to statements with each respondent receiving a score for both Deep and Surface approaches.

The R-SPQ was designed for full-time courses with examinations as the main method of assessment, therefore, the questionnaire was amended to make it more suitable for adult learners on blended learning courses. Biggs [2: 138] cites Eley [24] when he says inventories like the Study Process Questionnaire (SPQ) are often more sensitive when reworded for a particular subject. The changes made included; references to 'lecturers' have been amended to 'tutors', references to 'exams' have been amended to 'assessment', and 'course outlines' have been changed to 'course materials'.

\section{PRE-TEST AND PILOT TESTING OF THE QUESTIONNAIRES}

A pre-test of the learner questionnaire was carried out firstly by a colleague, a senior lecturer in elearning at the University, and secondly, with a group of learners, both of which resulted in some amendments.

A pilot study, using one tutor's module and seven of their learners, aided the development of the questionnaires. Oppenheim [25] states:

\begin{abstract}
Internal consistency method rests firmly on classical scaling theory. If the scale is expected to measure a single underlying continuum, then the items should have strong relationships both with that continuum and with each other. While we cannot observe the former, a scale will be internally consistent if the items correlate highly with each other - in which case they are also more likely to measure the same homogenous variable [25: 160].
\end{abstract}

To measure the scale reliability of the learner questionnaire as a measurement instrument, Cronbach's Alpha coefficient was used at both the pilot stage and the full survey testing (see Section 6) to evaluate the degree of item homogeneity. Whist there is some discussion about an acceptable Chronbach Alpha value indicating scale reliability (for example: see, [26]), Kline [27] argues that when dealing with complex, psychological constructs, values around $\alpha=.7$ can be acceptable and this was used as a guide to the questionnaire's development. (The actual Chronbach Alpha scores at the end of the pilot stage are stated in Table 1). 
Table 1 - Chronbach Alpha scores following pilot

\begin{tabular}{|l|c|}
\hline Questionnaire and Scale Item & Chronbach Alpha Value \\
\hline CEQ & 0.852 \\
\hline Clear Goals & 0.926 \\
\hline Good Teaching Communication & 0.437 \\
\hline Appropriate Workload & 0.825 \\
\hline Good Teaching Feedback & 0.358 \\
\hline Appropriate Assessment & 0.706 \\
\hline R-SPQ & \\
\hline Deep Learning & 0.706 \\
\hline Surface Learning & 0.598 \\
\hline
\end{tabular}

At the pilot stage, both the CEQ and R-SPQ did have some scales that resulted in unacceptable Chronbach Alpha scores $(\alpha<.7)$, but, given their previous testing (for example: see, Kreber, [7] and Zeegers, [20]) the statements were kept for the study, but checked for reliability and validity once all the questionnaire data was analysed. CEQ scale Appropriate Assessment had an acceptable value $(\alpha=$ .706) when the statement 'the tutor asked me questions about facts' was taken out. Both Good Teaching scale items, and the Surface scale on the R-SPQ, received concerning values $(\alpha<.7)$ but, had acceptable values when individual statements were not included. It was therefore decided that the statements would remain within the questionnaire and re-tested once all the data for the study was collected.

\section{FULL SURVEY TESTING OF THE QUESTIONNAIRES}

During the full survey of both questionnaires, scales were retested for reliability and found to be largely reliable. 72 responses to the questionnaires were received. Again, when dealing with complex, psychological constructs, Chronbach Alpha values around .7 can be acceptable [24] and was used as a guide for this stage of the development. (See Table 2 for all the Chronbach Alpha Values from the full survey testing).

The reliability score for the CEQ was acceptable $(\alpha=.871)$ as were the scores for the scales Clear Goals, Good Teaching Communication, and Good Teaching Feedback. The CEQ scale Appropriate Assessment was again problematic $(\alpha=.392)$ and, therefore, were removed from the research study's final analysis. This scale needs attention and development before further use. Appropriate Workload did not achieve an acceptable level of reliability $(\alpha=.599)$, however, due to CEQs extensive use in other empirical research, it was at a sufficient level to be used in the final analysis of the research study. However, again, further development is needed for this scale item before further use.

The R-SPQ achieved acceptable Chonbach Alpha scores (Deep $\alpha=.752$; Surface $\alpha=.725$ ), and, given its previous scrutiny for validity (for example: see, $[2 ; 20 ; 18 ; 19]$ ), provided confidence in the questionnaire's reliability.

Table 2 - Chronbach Alpha scores following the full survey

\begin{tabular}{|l|c|}
\hline Questionnaire and Scale Item & Chronbach Alpha Value \\
\hline CEQ & 0.871 \\
\hline Clear Goals & 0.839 \\
\hline Good Teaching Communication & 0.748 \\
\hline Appropriate Workload & 0.599 \\
\hline Good Teaching Feedback & 0.714 \\
\hline Appropriate Assessment & 0.392 \\
\hline
\end{tabular}




\begin{tabular}{|l|l|}
\hline R-SPQ & \\
\hline Deep Learning & 0.752 \\
\hline Surface Learning & 0.725 \\
\hline
\end{tabular}

Validity and reliability of the CEQ was further established by using a scatterplot and correlation with a similar construct. In order to determine whether the scales had acceptable content, concurrent and construct validity, Oppenheim [25: 162] recommends the use of external criteria. The CEQ scores were compared and correlated against a similar questionnaire, the Online Tutoring Questionnaire (OTQ) [4], which was designed to explore learner perceptions of the quality of online tutoring received during a module. This was undertaken with a view that both questionnaires were measuring different aspects of effective blended tutoring. Also, measures of effective tutoring were compared with learners' perception of achievement on modules as, it was assumed, effective tutors would lead to learners being successful. Significant relationships were found between the CEQ and OTQ $(r=.786, p<.01)$, and the CEQ and learner perception of their achievement $(T=.313, p<.01)$ (Kendall's tau coefficient $(T)$ was chosen here due to its value with "a small data set with a large number of tied ranks" [26: 131]). Field [26: 113] advises the use of simple scatterplots to identify outliers and to make observations of two data sets. Fig. 1 scatterplots the total mean tutor scores for the CEQ and OTQ.

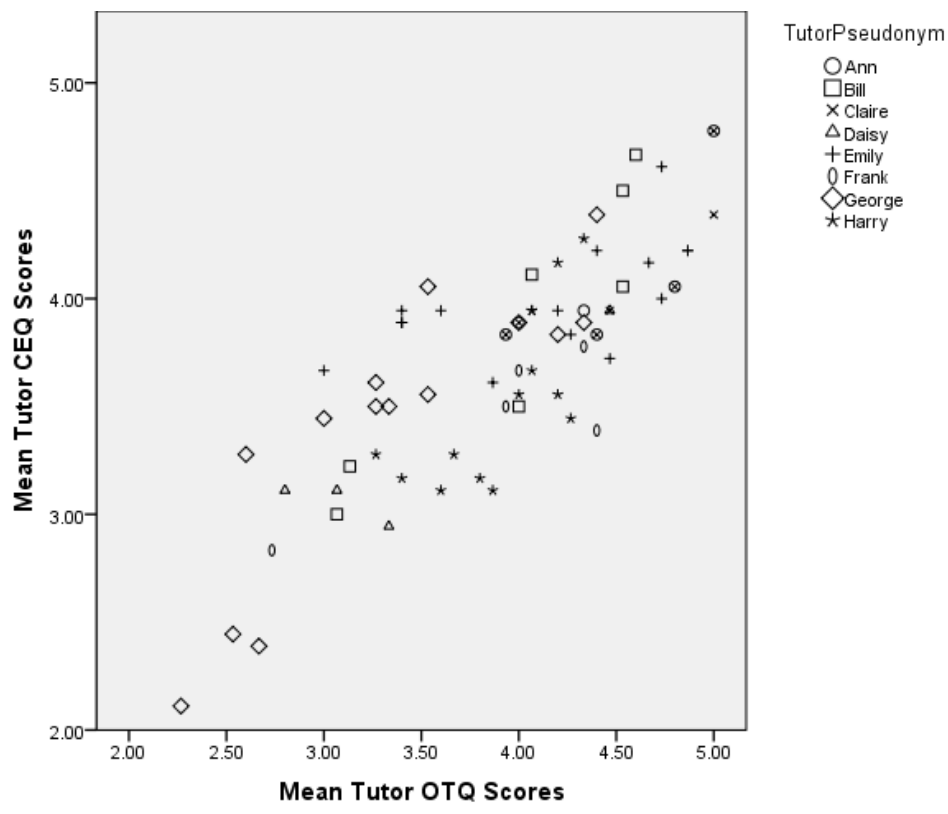

Figure 1 - A scatterplot to compare mean tutor CEQ scores (8 tutors in total) with mean tutor OTQ scores for each learner respondent.

From the scatterplot it is clear there is a positive correlation between the mean tutor CEQ and OTQ scores indicating measurement of a related construct. There were no significant outliers. The similar responses to both these questionnaires are interesting when considering the diversity of the survey statements. This may indicate that when learners are questioned regarding their tutor, their overall impression may influence their answer to a greater extent than the individual questions. However, even if this phenomenon was occurring, the questionnaire would still be eliciting learners' perceptions of the quality of blended tutoring they had received and, therefore, strengthened the confidence in the CEQ's value. The final versions of the modified CEQ and R-SPQ are detailed in Table 3 and Table 4 respectively.

Oppenheim [25: 168] recommends a correlation procedure such as factor analysis to further purify the scales. However, Field [26: 638] draws on a range of research to conclude the reliability of such analyses are weak with sample sizes below 100; therefore, factor analysis would not be suitable for a small-scale research project with 72 respondents. 
Table 3 - Items of the Modified Course Experience Questionnaire

\begin{tabular}{|c|c|}
\hline $\begin{array}{l}\text { Question } \\
\text { Number }\end{array}$ & Question \\
\hline \multicolumn{2}{|c|}{ Good Teaching: communication } \\
\hline 2 & The tutor of this module motivated me to do my best work \\
\hline 13 & The tutor was extremely good at explaining things \\
\hline 15 & The tutor worked hard on making the subject interesting \\
\hline \multicolumn{2}{|c|}{ Good Teaching: feedback on, and concern for, student learning } \\
\hline 5 & The tutor put a lot of time into commenting on my work \\
\hline $10^{*}$ & Feedback on my work was usually given only in the form of marks or grades \\
\hline 11 & $\begin{array}{l}\text { The tutor made a real effort to understand difficulties I might be having with my } \\
\text { work }\end{array}$ \\
\hline 12 & The tutor normally gave me feedback on how I was doing \\
\hline \multicolumn{2}{|c|}{ Clear Goals and Standards } \\
\hline 1 & It was easy to know the standard of work expected in this module \\
\hline 4 & $\begin{array}{l}\text { I usually had a clear idea of where I was going and what was expected of me in } \\
\text { this module }\end{array}$ \\
\hline $8^{*}$ & It was often hard to discover what was expected of me in this module \\
\hline 18 & The tutor made it clear right from the start what they expected from students \\
\hline \multicolumn{2}{|c|}{ Appropriate Workload } \\
\hline $3^{*}$ & The workload in this module was too heavy \\
\hline 9 & I was generally given enough time to understand things I had to understand \\
\hline $16^{*}$ & There was a lot of pressure on me to do well in this module \\
\hline $17^{*}$ & The sheer volume of work to get through in this module was too heavy \\
\hline \multicolumn{2}{|c|}{ Appropriate Assessment } \\
\hline $6^{*}$ & To do well in this module all you really needed was to rework the course notes \\
\hline $7^{*}$ & $\begin{array}{l}\text { The tutor seemed more interested in assessing learning outcomes than what I } \\
\text { had understood }\end{array}$ \\
\hline $14^{*}$ & The tutor asked me questions about facts \\
\hline
\end{tabular}

* $=$ reverse coded items.

Table 4 - Items for the Modified Revised Study Process Questionnaire 


\begin{tabular}{|c|c|}
\hline 1 & I find that at times studying gives me a feeling of deep personal satisfaction \\
\hline 2 & $\begin{array}{l}\text { I find that I have to do enough work on a topic so that I can form my own } \\
\text { conclusions before I am satisfied }\end{array}$ \\
\hline 3 & My aim is to pass the course while doing as little work as possible \\
\hline 4 & I only study seriously what's given out in class or in the module notes \\
\hline 5 & I feel that virtually any topic can be highly interesting once I get into it \\
\hline 6 & $\begin{array}{l}\text { I find most new topics interesting and often spend extra time trying to obtain } \\
\text { more information about them }\end{array}$ \\
\hline 7 & I do not find my course very interesting so I keep my work to the minimum \\
\hline 8 & I include things in my assignments that I do not fully understand \\
\hline 9 & $\begin{array}{l}\text { I find that studying academic topics can at times be as exciting as a good novel } \\
\text { or movie }\end{array}$ \\
\hline 10 & I test myself on important topics until I understand them completely \\
\hline 11 & $\begin{array}{l}\text { I find I can get by in most assessments by including key topics rather than trying } \\
\text { to understand them }\end{array}$ \\
\hline 12 & $\begin{array}{l}\text { I generally restrict my study to what is specifically set as I think it is unnecessary } \\
\text { to do anything extra }\end{array}$ \\
\hline 13 & I work hard at my studies because I find the material interesting \\
\hline 14 & $\begin{array}{l}\text { I spend a lot of my free time finding out more about interesting topics which have } \\
\text { been discussed in the module }\end{array}$ \\
\hline 15 & $\begin{array}{l}\text { I find it is not helpful to study topics in depth. It confuses and wastes time, when } \\
\text { all you need is a passing acquaintance with topics }\end{array}$ \\
\hline 16 & $\begin{array}{l}\text { I believe that tutors shouldn't expect students to spend significant amounts of } \\
\text { time studying material everyone knows won't be assessed }\end{array}$ \\
\hline 17 & I usually come to my tutor with questions in mind that I want answering \\
\hline 18 & $\begin{array}{l}\text { I make a point of looking at most of the suggested readings that go with the } \\
\text { course notes }\end{array}$ \\
\hline 19 & I see no point in learning material which is not likely to be assessed \\
\hline 20 & My approach was to do as little work as possible in order to pass the module \\
\hline
\end{tabular}

\section{RECOMMENDED FURTHER DEVELOPMENTS}

This paper, and the evidence contained within, is based on a small-scale research study within an education disciplinary context. The analysis of both the CEQ and R-SPQ was undertaken from 72 respondents and, therefore, further responses are required, from a variety of disciplinary areas, to enhance the questionnaires' reliability and validity within blended learning contexts.

As stated in the previous section, Oppenheim [25: 168] recommends a correlation procedure such as factor analysis to further purify questionnaire scales, following tests for reliability. Field [26: 638] draws 
on a range of research to conclude the reliability of such analyses are weak with sample sizes below 100 and, therefore, a factor analysis should be undertaken for both questionnaires when this number of respondents is exceeded.

Whilst the R-SPQ had acceptable Chronbach Alpha scores for both Deep and Surface scales, there were some issues with some of the CEQ's constituent sections. The Appropriate Assessment scale was problematic with revisions required and consideration should be given to including questions that are not negatively scored. As outlined in Section 5, the CEQ scale Appropriate Assessment had an acceptable value $(\alpha=.706)$ when the statement 'the tutor asked me questions about facts' was taken out. However, this was not found during the full survey testing of the research. Whilst less problematic, the Appropriate Workload scale needs some adjustments to enhance its reliability or, at least, further testing to see if reliability improves with a larger sample.

\section{CONCLUSION}

This paper has outlined work that contributed to a small-scale research study, which utilised modified versions of the Course Experience Questionnaire [1] and the Revised Study Process Questionnaire [2] within educational disciplinary contexts. Both demonstrated acceptable reliability $(\alpha>.7)$ at questionnaire level and, generally, across constituent scales, and these can be adopted for further research in similar contexts. Suggestions have made to further improve the validity and reliability of the questionnaires for future research in this area. I would welcome discussions with any researcher adopting these questionnaires regarding their value in blended learning contexts.

\section{REFERENCES}

[1] P. Ramsden, "A performance indicator of teaching quality in higher education: The Course Experience Questionnaire," Studies in Higher Education, vol. 16, pp. 129-150, 1991.

[2] J.B. Biggs, J. B., D. Kember, \& D. Y. P. Leung, "The revised two-factor Study Process Questionnaire: R-SPQ-2F," British Journal of Educational Psychology, vol. 71, pp. 133-149, 2001.

[3] L. De George-Walker \& M. Keeffe, "Self-determined blended learning: a case study of blended learning design," Higher Education Research \& Development, vol. 29, no 1, pp. 1-13, 2010.

[4] A. Youde, "A Mixed Methods Exploration of Effective Tutors and Tutoring in Blended Learning Contexts," Doctoral thesis, University of Huddersfield, 2014.

[5] A. Youde, "Tutor Emotional Competences Valued by Learners in a Blended Learning Context," European Journal of Open, Distance and E-Learning (EURODL), vol. 19, no. 2, pp. 81-97., 2016. ISSN 1027-5207.

[6] A. Youde, "Andragogy in blended learning contexts: effective tutoring of adult learners studying part-time, vocationally relevant degrees at a distance," International Journal of Lifelong Education, vol. 37, no. 2, pp. 255-272., 2018. doi: 10.1080/02601370.2018.1450303.

[7] C. Kreber, "The relationship between students' course perception and their approaches to studying in undergraduate science courses: a Canadian experience," Higher Education Research and Development, vol. 22, pp. 57-70, 2003.

[8] J. T. E. Richardson \& A. Woodley, "Perceptions of academic quality among students with a hearing loss in distance education," Journal of Educational Psychology, vol. 93, no. 3, pp. 563570, 2001.

[9] J. T. E. Richardson, "The attainment and experiences of disabled students in distance education," Distance Education, vol.30, no. 1, pp. 87-102, 2009.

[10]D. Laurillard, Rethinking University Teaching: a framework for the effective use of learning technologies, $2^{\text {nd }}$ ed., Abingdon, Oxfordshire: RoutledgeFalmer, 2002.

[11]J. Brindley, L. Blaschke \& C. Walti, "Creating Effective Collaborative Learning Groups in an Online Environment," The International Review of Research in Open and Distance Learning, 2009, Retrieved from http://www.irrodl.org/index.php/irrodl/article/view/675/1271.

[12] A. Lizzio, K. Wilson, \& R. Simons, "University students' perception of the learning environment and academic outcomes: implications for theory and practice," Studies in Higher Education, vol.27, no. 1, pp. 27-52, 2002. 
[13]K. L. Wilson, A. Lizzio \& P. Ramsden, "The development, validation, and application of the Course Experience Questionnaire," Studies in Higher Education, vol. 22, pp. 33-53, 1997.

[14]N. J. Entwistle \& P. Ramsden, Understanding student learning, London: Croom Helm, 1993.

[15] G. Gibbs, Improving the quality of student learning, Bristol: Technical and Educational Services, 1992.

[16] M. S. Knowles, E. F. Holton, \& R. A. Swanson, The Adult Learner: The Definitive Classic in Adult Education and Human Resource Development, $8^{\text {th }}$ ed., Oxford: Routledge, 2015.

[17]Y. J. Vermetten, H. G. Lodewijks, \& J. D. Vermunt, "Consistency and variability of learning strategies in different university courses," Higher Education, vol. 37, pp. 1-21, 1999.

[18]D. Y. P. Leung, P. Ginns, \& D. Kember, D "Examining the cultural specificity of approaches to learning in universities in Hong Kong and Sydney," Journal of Cross-Cultural Psychology, vol. 39, pp. 251-266, 2008.

[19]A. Stes, S. De Maeyer \& P. Van Petegem, "Examining the cross-cultural sensitivity of the Revised Two-Factor Study Process Questionnaire (R-SPQ-2F) and validation of a Dutch version," PloS one, Vol. 8, No. 1, 2013.

[20]P. Zeegers, "A Revision of the Biggs' Study Process Questionnaire (R-SPQ)," Higher Education Research and Development, vol. 21, no. 1, pp. 73-92, 2002.

[21]K. Marton \& R. Säljö "On qualitative differences in learning: I - Outcome and process," British Journal of Educational Psychology, vol. 46, pp. 4-11, 1976.

[22] J. Biggs \& C. Tang, Teaching for Quality Learning at University, $3^{\text {rd }}$ ed., Maidenhead: Open University Press, 2007.

[23] D. Kember, D. Y. P. Leung \& C. McNaught, "A workshop activity to demonstrate that approaches to learning are influenced by the teaching and learning environment," Active Learning in Higher Education, vol. 19, no. 1, pp. 43-56, 2008.

[24] M. G. Eley, "Differential adoption of study approaches within individual students," Higher Education, vol. 23, pp. 231-254, 1992.

[25] A.N. Oppenheim, Questionnaire Design, Interviewing and Attitude Measurement, London: Continuum, 1992.

[26] A. Field, Discovering Statistics Using SPSS, $4^{\text {th }}$ ed., London: Sage, 2013.

[27]P. Kline, The handbook of psychological testing, $2^{\text {nd }}$ ed., London: Routledge, 1999. 